\title{
Optimization of Molding Parameters Using Taguchi Method to Increase the Electrical Conductivity and Tensile Strength of Conductive Polymer Composites
}

\author{
H Suherman ${ }^{1}$, P Pulungan ${ }^{1}$, Y Yovial $^{1}$, and Irmayani² \\ ${ }^{1}$ Department of Mechanical Engineering, Universitas Bung Hatta, Padang, Indonesia \\ ${ }^{2}$ Department of Industrial Engineering, Universitas Ekasakti, Padang, Indonesia
}

\begin{abstract}
The focus of this research is to increase the electrical conductivity and tensile strength of conductive polymer composites (CPCs) materials using Taguchi method. The efforts made is by optimizing the molding parameters, using two different size of conductive fillers, ie G25 $(25 \mu \mathrm{m})$ and G13 $(13 \mu \mathrm{m})$ in producing CPCs material. The molding parameters used are molding time and molding temperature. S/N ratio is use to obtain the optimum molding parameters, ie the larger is better. The results showed that Taguchi method L9 $\left(2^{3}\right)$ succeeded in increasing the electrical conductivity and tensile strength of G25/G74/epoxy and G13/G74/epoxy composites. The highest electrical conductivity and tensile strength is on G13/G74/epoxy composites, ie $3.51 \mathrm{~S} / \mathrm{cm}$ and $155.50 \mathrm{~N} / \mathrm{mm}^{2}$ respectively.
\end{abstract}

\section{Introduction}

The electrical conductivity and mechanical properties such as tensile strength are important properties to be possessed by a conductive polymer composite material. To obtain the optimum value for these both properties, it is necessary to optimize the parameters of the molding process. The parameters of the molding process used to produce the conductive polymer composites (CPCs) material are greatly affect the properties of the CPCs material produced [1-3]. Suherman et al. [1] conducted research on the effect of content, molding temperature, and molding pressure on the electrical conductivity of carbon nanotub (CNTs)/graphite/epoxy composite. The results showed that the incorporation of CNTs and graphite as a conductive materials produced a synergistic effect in improving electrical conductivity, as well as molding temperatures and molding pressure. The influence of the molding parameters of CNTs/graphite/epoxy nanocomposites to the in-plane and through-plane electrical conductivities has been observed by Suherman et al. [2]. They reported that the incorporation of CNTs and graphite materials had a positive effect in improving the electrical conductivity values of in-plane and through-plane directions, to a CNT content until 5 weight percentage (wt.\%). The Taguchi method has widely used to obtain the optimum value of a molding parameter. Thanapat Sangkharat and Surangsee Dechjarern [3] conducted research on spinning process design. Ahmer et al. [4] examined the effect of time on the use of fly ash. Yizong et al. [5] analyzed the effect of molding parameters on the injection molding process using polyestyrene matrix material. Sapana et al. [6] studied the benefits of benzeneacetic acid removal using $\mathrm{CaO} 2$ nanoparticles. This research use the Taguchi method L9 $\left(2^{3}\right)$ to optimize the molding parameters consisting of molding time and molding temperature using a second conductive filler with different sizes and shapes to increase the electrical conductivity and the tensile strength of the resulting conductive polymer composites.

\section{Experimental}

\subsection{Materials}

The conductive fillers used were graphite with three different sizes, ie $74 \mu \mathrm{m}$ (G74), $25 \mu \mathrm{m}$ (G25), and $13 \mu \mathrm{m}$ (G13). G74 which has a larger particle size, is used as the main filler, whereas G25 and G13 which has a smaller particle size are used as the second filler. The conductive fillers used as main and second fillers have different shapes, namely flakes and sphere shapes. G74 is obtained from Asbury Carbon America, while G25 and G13 are obtained from FRIway Industry, China. Epoxy resin at 6 Poise viscosity is obtained from US Composites. The description of particle size, the main and the second conductive fillers, as well as the viscosity of the epoxy resin used are obtained from the manufacturer.

\subsection{The manufacturing of G25/G74/epoxy and G13/G74/epoxy composites}

The composition based on weight percentage (wt.\%) of the main, second conductive fillers and epoxy resin as the matrix are shown in Table 1. The manufacturing process of G25/G74/epoxy and G13/G74/epoxy composites is by stirring resin and hardener using a mechanical stirring machine (IKA RW 20 Digital) for 10 minutes at $25 \mathrm{rpm}$ rotation. Furthermore, the main and second conductive 
fillers (G25, G13 and G74) as the predefined compositions are combined with epoxy resin mixture. The G25/G74/epoxy and G13/G74/epoxy mixture are

Table 1. Composition of G25/G74/epoxy and G13/G74/epoxy composites

\begin{tabular}{cccc}
\hline \multirow{2}{*}{ CPCs material } & \multicolumn{3}{c}{ Composition (wt.\%) } \\
\cline { 2 - 4 } & Second fillers & Main filler & Epoxy resin \\
\hline G25/G74/epoxy composites & G25:5, 7.5, 10 & G74 : 45, 42.5, 40 & 50 \\
G13/G74/epoxy composites & G13:5, 7.5, 10 & G74 : 45, 42.5, 40 & 50 \\
\hline
\end{tabular}

\subsection{Characterization}

The electrical conductivity and tensile strength of G25/G74/epoxy and G13/G74/epoxy composites material produced by different molding process parameters were measured using ASTM C 61 [7] and ASTM D3039, respectively. Scanning electron microscopy (SEM) with type S-3400 N (Hitachi) use to see the spread of main and second conductive fillers in epoxy resin. poured into an aluminum mold. The mold is then put into the oven for 90 minutes at $150^{\circ} \mathrm{C}$.

Composition (wt.\%)

\subsection{Control factors and levels of molding parameters}

The control factors of molding parameters are molding time $\left(\mathrm{A}_{\mathrm{mt}}\right)$, and molding temperature $\left(\mathrm{B}_{\mathrm{mt}}\right)$. Table. 2 show two control factors with three levels of molding parameters. The molding time levels $\left(\mathrm{A}_{\mathrm{mt}}\right)$ are 60,75 , and $90 \mathrm{~min}$, while the levels of molding temperature $\left(\mathrm{B}_{\mathrm{mt}}\right)$ are 110,130 and $150^{\circ} \mathrm{C}$.

Table 2. Factors and levels of molding parameters

\begin{tabular}{lllccc}
\hline \multirow{2}{*}{ Symbol } & \multirow{2}{*}{ Factors } & \multirow{2}{*}{ Unit } & \multicolumn{3}{c}{ Level } \\
\cline { 4 - 6 } & & & 1 & 2 & 3 \\
\hline $\mathrm{A}_{\mathrm{mt}}$ & Molding time & Minute & 60 & 75 & 90 \\
$\mathrm{~B}_{\mathrm{mt}}$ & Molding temperature & ${ }^{0} \mathrm{C}$ & 110 & 130 & 150 \\
\hline
\end{tabular}

\section{Results and discussion}

\subsection{Characterization of main and second conductive fillers}

Figure 1. shows the main and second conductive filler type used to produce G25/G74/epoxy and G13/G74/epoxy composites. SEM images shows that G74 as the main conductive filler has a flake shape. While G25 and G13 have flake and sphere shape.

\subsection{The electrical conductivity of G25/G74/epoxy and G13/G74/epoxy composites}

Table 3 shows the electrical conductivity generated using the molding parameters based on the Taguchi array L9 $\left(2^{3}\right)$ in generating G25/G74/epoxy and
G13/G74/epoxy composites. All parameters of the molding parameters used in this study show that G25/G74/epoxy and G13/G74/epoxy composites have different electrical conductivity. This indicates that all of the molding parameters used have an effect on the dispersion and the formation of conductive networks in the matrix polymer [8-10].

Table 3. shows that the size $(25 \mu \mathrm{m}$ and $13 \mu \mathrm{m})$, as well as different forms (sphere and flake) of conductive fillers produce different electrical conductivity. The 9 runs performed on two different sizes and shapes of conductive fillers showed that the smaller particle size $(13 \mu \mathrm{m})$ of the same shape produce the highest electrical conductivity of $2.92 \mathrm{~S} / \mathrm{cm}$ (run 1). This is due to the same shape of the smaller secondary conductive filler is more effective in filling the cavity formed by the main conductive filler.

Table 3. Taguchi array L9 $\left(2^{3}\right)$ of molding parameters

\begin{tabular}{ccccc}
\hline Run & \multicolumn{2}{c}{ Factor and level } & \multicolumn{2}{c}{ Electrical conductvity $(\mathrm{S} / \mathrm{cm})$} \\
& A (molding time) & B (molding temperature) & $13 \mu \mathrm{m}$ & $25 \mu \mathrm{m}$ \\
\hline 1 & 60 & 110 & 2.92 & 1.41 \\
2 & 60 & 130 & 2.26 & 2.72 \\
3 & 60 & 150 & 2.4 & 2.37 \\
4 & 75 & 110 & 2.57 & 1.49 \\
5 & 75 & 130 & 1.28 & 1.13 \\
6 & 75 & 150 & 2.78 & 2.07 \\
7 & 90 & 110 & 2.44 & 1.61 \\
8 & 90 & 130 & 2.74 & 1.58 \\
9 & 90 & 150 & 2.86 & 1.30 \\
\hline
\end{tabular}




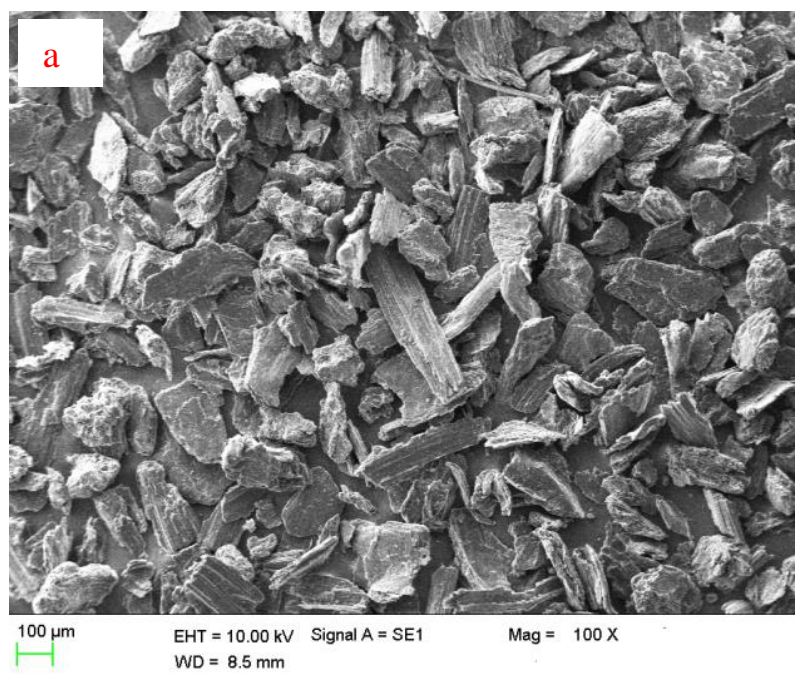

G74 $(74 \mu \mathrm{m})$

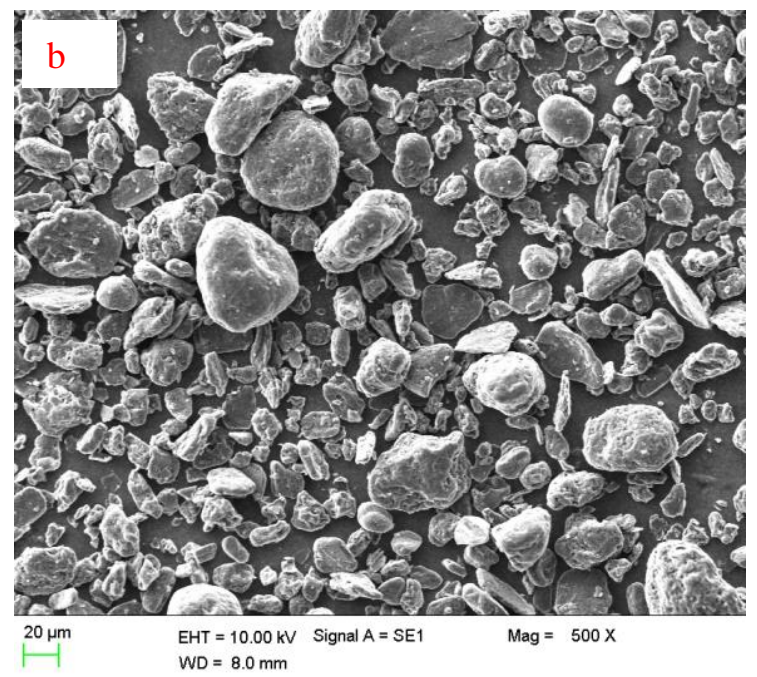

$\mathrm{G} 25(25 \mu \mathrm{m})$

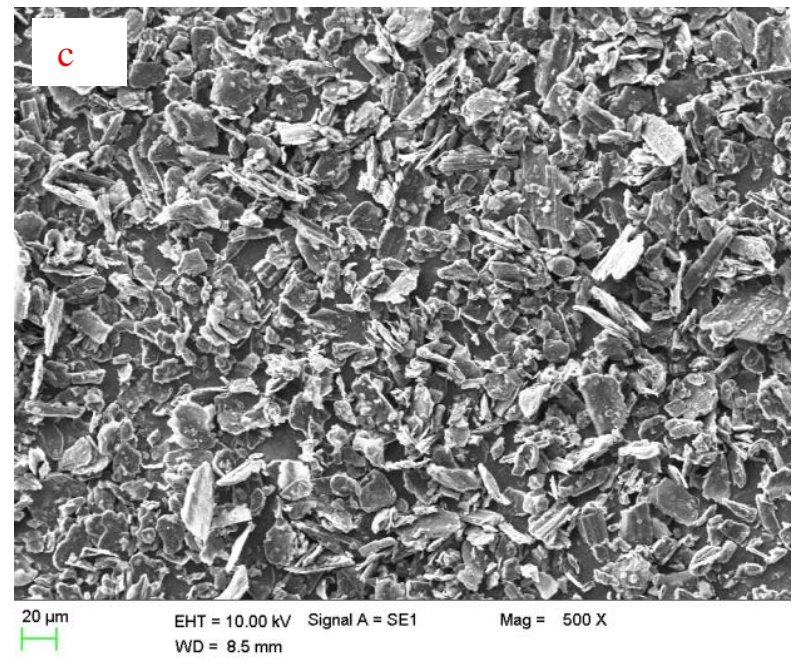

$\mathrm{G} 13(13 \mu \mathrm{m})$

Figure 1. SEM images: (a) G74, (b) G25 and (c) G13

\subsection{Taguchi response on molding paremeters based on $\mathrm{S} / \mathrm{N}$ ratio}

Figures 2 and 3 show the $\mathrm{S} / \mathrm{N}$ ratio of the molding parameters using particle size 13 and $25 \mu \mathrm{m}$ as the second conductive filler. The optimum parameters at $\mathrm{A}_{3}(90$ minutes heating time), $\mathrm{B}_{3}$ (molding temperature $150{ }^{\circ} \mathrm{C}$ ) were obtained on the molding parameters of $13 \mu \mathrm{m}$ particle size (flake shape). While in particle size $25 \mu \mathrm{m}$ (sphere shape), the optimum molding parameter obtained are $\mathrm{A}_{1}$ (moding time, 60 minutes), and $\mathrm{B}_{3}$ (molding temperature, $150^{\circ} \mathrm{C}$ ). Thus, the optimum molding parameters recommended by Taguchi array L9 $\left(2^{3}\right)$, (larger is better) then followed by specimens of G25/G74/epoxy and G13/G74/epoxy composites.

The Taguchi recommendations for two conductive fillers and tensile strength of different sizes and shapes are shown in Table 4. The highest electrical conductivity based on Taguchi recomendation was obtained on G13/G74/epoxy composites of $3.51 \mathrm{~S} / \mathrm{cm}$ and $2.80 \mathrm{~S} / \mathrm{cm}$ in $\mathrm{G} 25 / \mathrm{G} 74 /$ Epoxy composites. So as tensile strength, the value obtained by a smaller conductive filler $(13 \mu \mathrm{m})$ of $155.50 \mathrm{~N} / \mathrm{mm}^{2}$ is greater when compared with a larger second filler $(25 \mu \mathrm{m})$ of $140.42 \mathrm{~N} / \mathrm{mm}^{2}$. The results obtained are in line with Antunes et al. [11] which states that the second conductive filler will be effective if the particle size is smaller if the conductive filler more than one. 


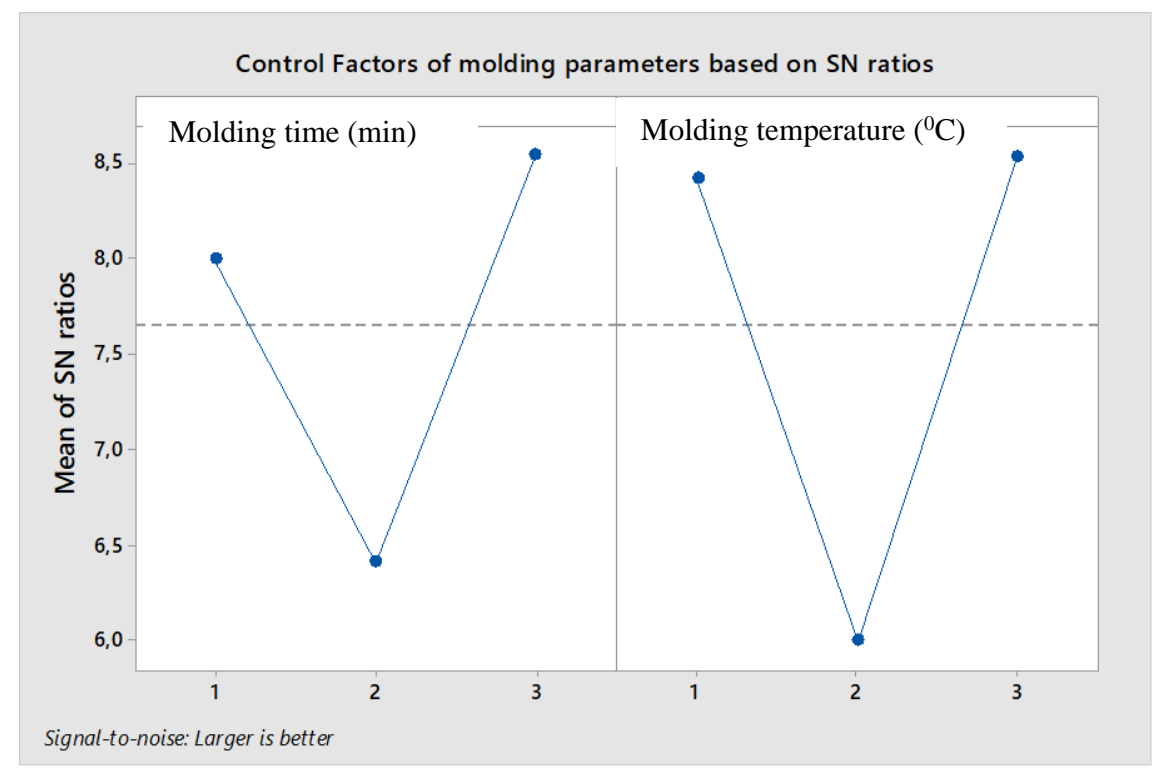

Figure 2. Control factors of molding parameters based on $\mathrm{S} / \mathrm{N}$ ratio for particle size $13 \mu \mathrm{m}$

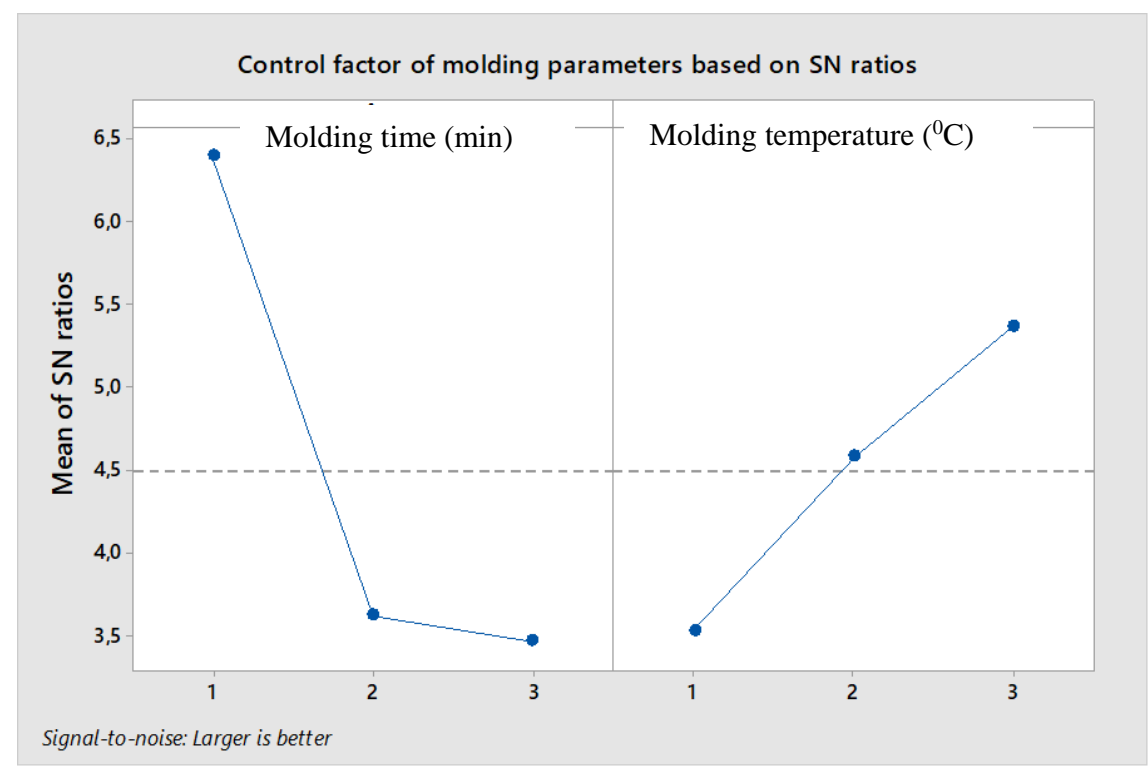

Figure 3. Control factor of molding parameters based on $\mathrm{S} / \mathrm{N}$ ratio for particle size $25 \mu \mathrm{m}$

Table 4. Taguchi recommendation of molding parameters based on Taguchi array L9 $\left(2^{3}\right)$

\begin{tabular}{|c|c|c|c|c|}
\hline No & $\begin{array}{c}\text { G13/G74/epoxy and } \\
\text { G25/G74/epoxy composites }\end{array}$ & $\begin{array}{l}\text { Particle size of } \\
\text { conductive filler }\end{array}$ & Electrical conductivity $(\mathrm{S} / \mathrm{m})$ & $\begin{array}{l}\text { Tensile strength } \\
\left(\mathrm{N} / \mathrm{mm}^{2}\right)\end{array}$ \\
\hline 1 & Run 1 & $13 \mu \mathrm{m}$ (flake shape) & 2,92 & 145,50 \\
\hline 2 & Taguchi recomendation & & 3,51 & 155,50 \\
\hline 3 & Run 1 & $25 \mu \mathrm{m}$ (sphere shape) & 1,41 & 127,72 \\
\hline 4 & Taguchi recomendation & & 2,80 & 140,42 \\
\hline
\end{tabular}



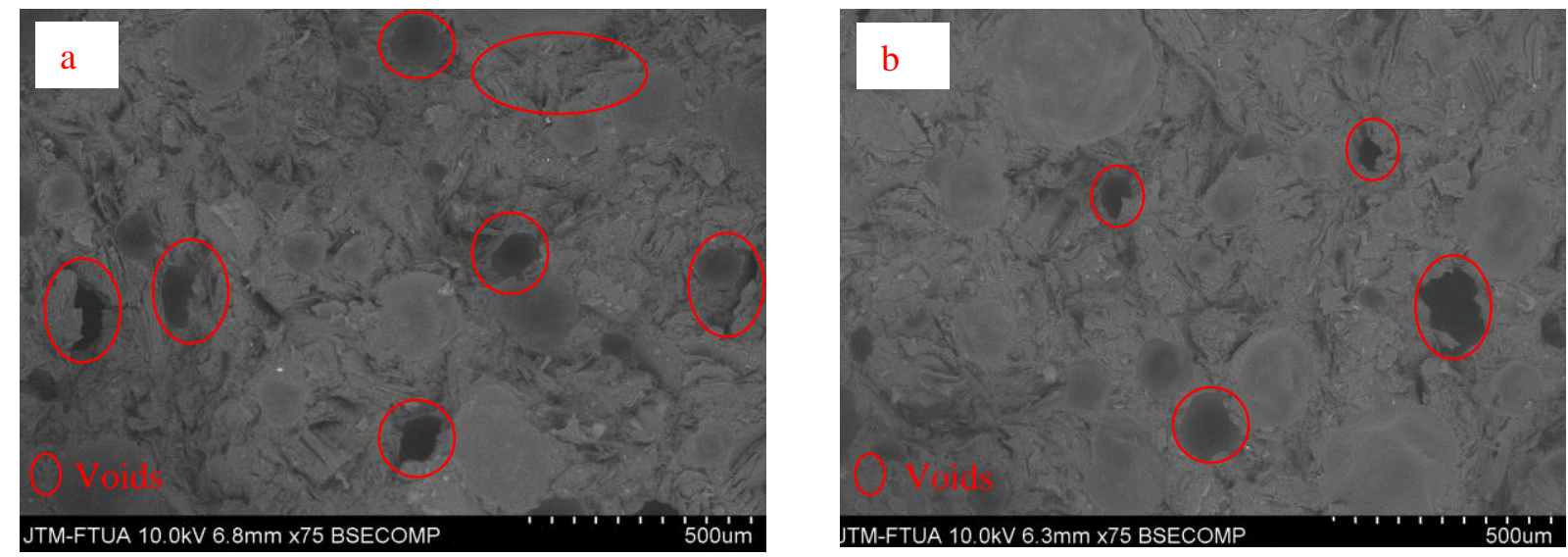

Run 1, particle size of $13 \mu \mathrm{m}$

Taguchi recomendation, particle size of $13 \mu \mathrm{m}$

Figure 4. SEM images of fracture surface of G13/G74/epoxy composites (a) Run 1, (b) Taguchi recommendation

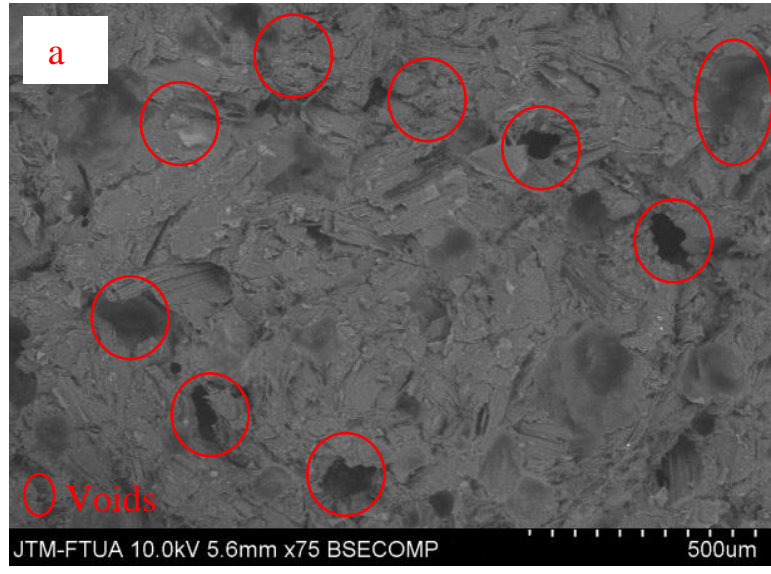

Run 1, particle size of $25 \mu \mathrm{m}$

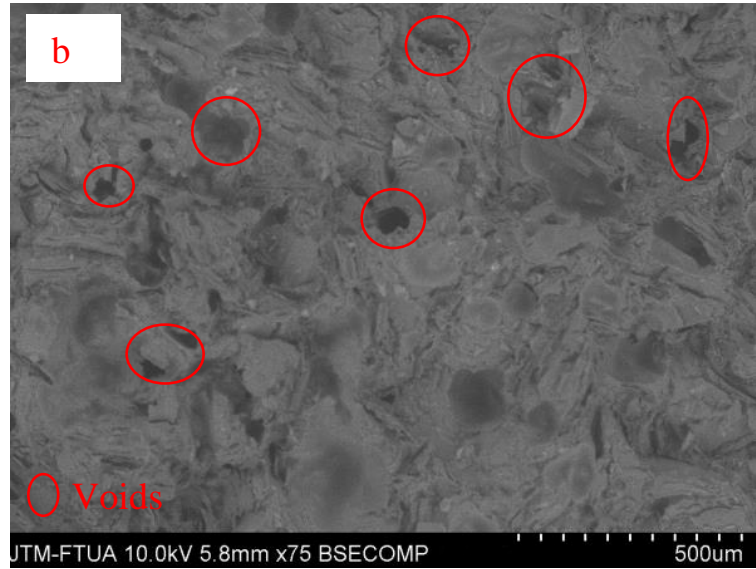

Taguchi recommendation, particle size of $25 \mu \mathrm{m}$

Figure 5. SEM images of fracture surface of G25/G74/epoxy composites (a) Run 1, (b) Taguchi recommendation

Figure 4. shows that run 1 of G13/G74/epoxy composite (fig.4a) has more voids compare than the G13/G74/epoxy composite (fig.4b) generated from Taguchi recommendations. Similarly, Fig. 5 shows voids formed on G25 / G74 / epoxy composite materials (fig.5a) is more than the composite materials made based on Taguchi recommendations (fig 5b). This causes the electrical conductivity and tensile strength at run 1 lower than the Taguchi recommendation $[12,13]$.

\section{Conclussion}

The Taguchi method L9 $\left(2^{3}\right)$ has been used to optimize the molding parameters of G25/G74/Epoxy and G13/G74/Epoxy composites. This method successfully increases the electrical conductivity and tensile strength the composite. Both the second conductive fillers used (G25 and G13) have succeeded in increasing the electrical conductivity and tensile strength for G25/G74/epoxy and G13/G74/epoxy composites. The G13/G74/epoxy composite increased the electrical conductivity and tensile strength from $2.92 \mathrm{~S} / \mathrm{cm}$ to $3.51 \mathrm{~S} / \mathrm{cm}(20.21 \%)$ and 145.5 $\mathrm{N} / \mathrm{mm} 2$ to $155.50 \mathrm{~N} / \mathrm{mm} 2 \quad(6.87 \%)$. While on G25/G74/epoxy composite, the electrical conductivity increased from $1.41 \mathrm{~S} / \mathrm{cm}$ to $2.80 \mathrm{~S} / \mathrm{cm}(98.58 \%)$ and tensile strength increased from $127.72 \mathrm{~S} / \mathrm{cm}$ to 140.42 $\mathrm{S} / \mathrm{cm}(9.94 \%)$. This condition indicates that the Taguchi method L9 $\left(2^{3}\right)$ used effectively improves the electrical conductivity and tensile strength of the resulting G13/G74/Epoxy and G25/G74/Epoxy composites.

\section{Acknowledgment}

The authors gratefully acknowledge the financial support given for this work by the Directorate General of Higher Education through the applied research of excellent 
university under contarct number: 023-34/LPPMPenelitian/Hatta/II-2018.

\section{References}

1 H. Suherman, A.B. Sulong, J. Sahari. Int. J. Mech. Mater. Eng. 5, 74 (2010)

2 H. Suherman, A.B. Sulong, J. Sahari. Ceram. Int. 39, 1277 (2013)

3 T. Sangkharat, S. Dechjarern. Procedia Eng. 207, 1713 (2017)

4 A.A. Siyal, K.A. Azizli, Z. Mana, H. Ullah. Procedia Eng. 148, 302 (2016)

5 T. Yizong, Z.M. Ariff, A.M. Khalil. Procedia Eng. 184, 350 (2017)

6 S.M. Sapana,L. Kailas, Wasewar. J. Appl. Res. Technology 15, 332 (2017)
7 B.K. Kakati, D. Sathiyamoothy, A. Verma. Int. J. Hydrogen Energy 35, 4185 (2010)

8 P.C. Ma, M.Y. Liu, H. Zhang, S.Q. Wang, R. Wang, K.Wang, Y.K. Wong, B.Z. Tang, S.H. Hong, K.W. Paik, J.K. Kim. ACS Appl.Mater.Interfaces 1, 1090 (2009)

9 N. Hu, Z. Masuda, G. Yamamoto, H. Fukunaga, T. Hashida, J. Qiu. Composites Part A 39, 893 (2008)

10 H. Suherman, A.B. Sulong, M.Y. Zakaria, N.R. Rajendra Royan, J. Sahari. Songklanakarin J. Sci. Technol. 40, 105 (2018)

11 R.A. Antunes, C.L. Mara, de Oliveira, Ett. Gerhard, Ett. Volkmar. J. Power Sources 196, 2945-2961 (2011)

12 H. Suherman, A.B. Sulong, J. Sahari. Adv. Mater. Res. 264-265, 559 (2011)

13 N.R. Rajendran Royan, A.B. Sulong, J. Sahari, H. Suherman. Journal of Nanomaterials 2013 Article ID 717459 (2013) 